\title{
Tribological and anti-corrosion performance of epoxy resin composite coatings reinforced with differently sized cubic boron nitride (CBN) particles
}

\author{
Zhiping HUANG ${ }^{1,2}$, Wenjie ZHAO ${ }^{1,2, *}$, Wenchao ZHAO ${ }^{1,2}$, Xiaojing $\mathrm{CI}^{1}$, Wentao $\mathrm{LI}^{1}$ \\ ${ }^{1}$ Key Laboratory of Marine Materials and Related Technologies, Zhejiang Key Laboratory of Marine Materials and Protective \\ Technologies, Ningbo Institute of Materials Technology and Engineering, Chinese Academy of Sciences, Ningbo 315201, China \\ ${ }^{2}$ University of Chinese Academy of Sciences, Beijing 100049, China
}

Received: 20 June 2019 / Revised: 07 August 2019 / Accepted: 11 September 2019

(C) The author(s) 2019.

\begin{abstract}
A series of high solid content (30 wt\%) epoxy resin (EP) composite coatings reinforced with differently sized cubic boron nitride (CBN) particles were fabricated successfully on 304L stainless steel. Polydopamine (PDA) was used to improve the dispersibility of CBN particles in EP. The structural and morphological features of the CBN particles and the composite coatings were characterized by Raman spectroscopy, scanning electron microscopy (SEM), and transmission electron microscopy (TEM). Moreover, a UMT-3 tribometer and surface profiler were used to investigate the tribological behaviors of the as-prepared composite coatings. Electrochemical impedance spectroscopy (EIS) and Tafel analysis were used to investigate the coatings' anti-corrosion performance. The results demonstrated that the CBN fillers could effectively enhance the tribological and anti-corrosion properties of the EP composite coatings. In addition, when the additive proportion of the microsized $(5 \mu \mathrm{m})$ and nanosized (550 nm) CBN particles was 1:1, the tribological property of the EP composite coatings was optimal for dry sliding, which was attributed to the load carrying capability of the microsized CBN particles and the toughening effect of the nanosized CBN particles. However, when the additive proportion of the microsized and nanosized CBN particles was 2:1, the tribology and corrosion resistance performance were optimal in seawater conditions. We ascribed this to the load-carrying capacity of the microparticles, which played a more important role under the seawater lubrication condition, and the more compact structure, which improved the electrolyte barrier ability for the composite coatings.
\end{abstract}

Keywords: epoxy resin; cubic boron nitride; size; composite coating; wear resistance; anti-corrosion

\section{Introduction}

Epoxy resin (EP) has been widely used as an adhesive, a coating, and an automotive and aeronautics material in many fields due to its excellent chemical resistance, mechanical behavior, and electrical insulating properties [1-3]. However, the wear resistance of pure EP is poor, which is mainly due to the 3D network structure formed during curing, and the self-lubricity of the polymer is not exhibited for cracks generated under friction conditions $[4,5]$. Therefore, there are few applications of neat EP under friction conditions, and EP must be made into a composite material to enhance its tribological performance so as to cater to different needs, especially in harsh environments. At present, incorporating micro/nanoparticles into EP is a widely accepted approach to promoting wear resistance, and is effective and low in cost. For example, nanodiamonds [6], $\mathrm{TiO}_{2}$ [4], $\mathrm{SiO}_{2}$ [7], graphene oxide [8], carbon nanotubes [9], and other micro/nanofillers have been used

* Corresponding author: Wenjie ZHAO, E-mail: zhaowj@nimte.ac.cn 
to greatly promote the tribological properties of EP. Similarly, EP has been widely used as a protective coating to protect metals from corrosion because of its outstanding processability, excellent chemical resistance, good electrical insulation properties, and strong adhesion to heterogeneous materials [3, 10]. $\mathrm{TiO}_{2}$ [11], $\mathrm{SiO}_{2}$ [1], graphene oxide [10], and other micro/nanofillers have also been used to further greatly promote the corrosion resistance of EP.

Polymer reinforced with differently sized particles shows different mechanical properties, including Young's modulus, strength, hardness, and toughness, which have a significant impact on its tribological performance [12]. Cho et al. [13] investigated the mechanical properties of polymer reinforced with spherical alumina particles. It was found that the Young's modulus of the composite increased as the size of the particles decreased at a nanoscale, and the tensile strength of the composite increased as the particle size decreased. Singh et al. [14] investigated the fracture toughness of thermoset unsaturated polyester resin reinforced with aluminum particles of micro- and nanometer size. It was observed that the overall fracture toughness increased monotonically as the volume fraction increased for a given particle size, and smaller particles led to a greater increase in fracture toughness for a given particle volume fraction. However, for the composite, larger particles increased the load-carrying capability and stiffness, which depends significantly on the load-carrying capability. Barmouz et al. [15] fabricated copper-base composites reinforced with $30 \mathrm{~nm}$ and $5 \mu \mathrm{m} \mathrm{SiC}$ particles on the surface of pure copper, and showed that decreasing the reinforcing particle size would enhance the tensile strength and wear resistance, and also decease the percent elongation. At the same time, composites reinforced with differently sized particles displayed different results in terms of compactness, dispersibility, and barrier, which significantly influenced their anticorrosion behaviors under water conditions. Li et al. [16] investigated the anti-corrosion behaviors of nano $\mathrm{SiO}_{2}$-modified EP coatings, and Mostafaei et al. [17] investigated the anti-corrosion behaviors of $\mathrm{ZnO}$ nanoparticle-modified polyaniline coatings. The results showed that nano composite coatings can act as either a physical barrier toward a corrosive environment, or as inhibitory pigments by shifting the corrosion potential of the metallic substrate to higher values and reducing the corrosion rate. However, nanoparticles easily agglomerate due to the large surface area, which makes it difficult to achieve high content (usually less than $1.0 \mathrm{wt} \%$ ). The addition of microparticles can also improve the dispersion of nanoparticles to some extent.

As a new type of micro/nanomaterial, boron nitride possesses a variety of crystalline structures, such as hexagonal and cubic [18-21]. Cubic boron nitride (CBN), whose hardness is second only to diamond, has been widely used in the field of wear resistance. $\mathrm{Yu}$ et al. [3] compared the tribological properties of EP composite coatings reinforced with functionalized CBN or hexagonal boron nitride (HBN) fillers. The results showed that $\mathrm{CBN}$ fillers endowed the EP composite coatings with higher wear resistance.

Inspired by the above research, CBN microparticles with a mean diameter of $5 \mu \mathrm{m}$, and CBN nanoparticles with a mean diameter of $550 \mathrm{~nm}$ were chosen to cooperatively improve the wear resistance and anticorrosion performance of EP. In this work, CBN particles of different sizes were first modified via the self-polymerization of dopamine. After that, a series of EP composite coatings reinforced with various proportions of macro-CBN (MCBN) and nano-CBN (NCBN) particles were fabricated. The surface modification of CBN particles and the mechanical properties of the composite coating were examined. The surface morphologies of the as-prepared composite coatings were observed. The tribological behaviors of the as-prepared composite coatings were investigated. Electrochemical impedance spectroscopy (EIS) was used to investigate the coatings' anti-corrosion performance. Finally, the tribological mechanism of the composite coating was elaborated based on the above results. We believe this binary-scale particle enhancement strategy for composites may extend their potential application areas, especially under harsh environments.

\section{Experimental}

\subsection{Materials}

The bisphenol-A EP TC-K44 (EP: epoxide value of 210-230 g/mol) and curing agent T31 (amine value of $460-480 \mathrm{mgKOH} / \mathrm{g}$ ) was purchased from Jiangyin 
Chemicals Co., Ltd., China. CBN particles were supplied by FUNIK Ultrahard Material Co., Ltd., China. In addition, dopamine hydrochloride was purchased from Aladdin Reagent Co. Ltd., China, and solvents including xylene and alcohol were purchased from Sinopharm Chemical Reagent Co., Ltd., China.

\subsection{Surface modification of CBN particles}

Because the surface of the CBN particle has few functional groups, further surface hydroxylation is required to achieve better graft efficiency. The schematic diagram of the surface modification process for CBN particles was shown in Scheme 1. First, the CBN particles were treated in a $5 \mathrm{M} \mathrm{NaOH}$ solution at $120^{\circ} \mathrm{C}$ for $24 \mathrm{~h}$, then washed with deionized water and centrifuged several times to neutral. The hydroxylated $\mathrm{CBN}$ was then dried in a furnace at $60^{\circ} \mathrm{C}$ for $5 \mathrm{~h}$, and collected after cooling. To dispel the aggregation caused by high activity, micro/nano-CBN particles were treated with dopamine hydrochloride, so that after chemical modification the CBN fillers would be well-dispersed in the EP matrix. $5 \mathrm{~g}$ of CBN particles was dispersed in a mixed solution of $800 \mathrm{~mL}$ of tris buffer solution (10 mM, pH 8.5). $100 \mathrm{mg}$ and $250 \mathrm{mg}$ of dopamine hydrochloride was added to the microsized and nanosized CBN particle solutions, respectively, and then the mixtures were stirred for $12 \mathrm{~h}$ at $25^{\circ} \mathrm{C}$. After the reaction, the modified $\mathrm{CBN}$ powder, denoted separately as MCBN@PDA and NCBN@PDA, was centrifuged and washed with deionized water and ethanol several times before being dried at $60^{\circ} \mathrm{C}$.

\subsection{Preparation of EP composite coatings}

A series of CBN-EP composite coatings with different micro/nano proportions (the formulations of the CBN-EP composite coatings are listed in Table 1) were prepared as follows: micro/nano-CBN@PDA was dispersed in EP by ultrasound for $10 \mathrm{~min}$, then a curing agent was added, stirred for $10 \mathrm{~min}$, and degassed at

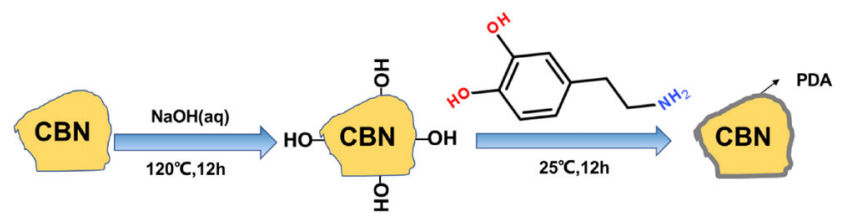

Scheme 1 Schematic illustration of the surface modification of CBN micro-/nanoparticles by dopamine.
Table 1 The formulation of CBN-EP composite coatings.

\begin{tabular}{ccccc}
\hline Sample & $\begin{array}{c}\text { EP } \\
\text { content } \\
(\%)\end{array}$ & $\begin{array}{c}\text { CBN } \\
\text { content } \\
(\%)\end{array}$ & $\begin{array}{c}\text { Micro-CNB } \\
\text { content }(\%)\end{array}$ & $\begin{array}{c}\text { Nano-CNB } \\
\text { content }(\%)\end{array}$ \\
\hline EP & 70 & 30 & 0 & 0 \\
CBN-EP-1 & 70 & 30 & 30 & 0 \\
CBN-EP-2 & 70 & 30 & 20 & 10 \\
CBN-EP-3 & 70 & 30 & 15 & 15 \\
CBN-EP-4 & 70 & 30 & 10 & 20 \\
CBN-EP-5 & 70 & 30 & 0 & 30 \\
\hline
\end{tabular}

room temperature for 10 min with a vacuum pump to remove the bubbles. Finally, the mixture was coated on the 304L stainless steel surface in a thickness of $300 \mu \mathrm{m} \pm 5 \mu \mathrm{m}$ for the tribological test, and on the Q235 level steel surface in a thickness of $20 \mu \mathrm{m} \pm 2 \mu \mathrm{m}$ for the corrosion test.

\subsection{Characterization}

The size distribution of the micro-CBN particles was measured by a micrometer laser particle size analyzer (S3500, S3500-special, American Microtrac). The size distribution of the micro-CBN particles was detected by dynamic light-scattering particle size analyzers (ZETA, Zetasizer Nano ZS, Malvern, United Kingdom). Thermogravimetric analysis (TGA, Diamond TG/DTA) was used to characterize the successful grafting and mass percentage of polydopamine (PDA) on the surface of the $\mathrm{CBN}$ particles. The heating rate was $10{ }^{\circ} \mathrm{C}$ per minute in the temperature range of 40 to $800{ }^{\circ} \mathrm{C}$ in air conditions. Raman spectrum (RAM, Renishaw inVia Reflex) and transmission electron microscopy (TEM, Tecnai F20) were used to detect the presence of PDA, and its thickness on the surface of CBN particles. Dynamic mechanical analysis (DMA, DMAQ800) and 5567 universal material testing (Instron 5569A) were carried out to investigate the thermal and mechanical properties of CBN-EP composite coatings. The hardness of the coatings was characterized by Vickers hardness testing.

\subsection{Tribological and corrosion measurements}

The tribological behaviors of neat EP and CBN composite coatings were examined with a UMT-3 tribometer (CETR, USA) with a reciprocating ball-on-plate mode. The experimental parameters were as follows: the 
load was 5 and $10 \mathrm{~N}$ under dry sliding and seawater conditions, respectively, frequency was $5 \mathrm{~Hz}$, wear track distance was $5 \mathrm{~mm}$, sliding time was $30 \mathrm{~min}$, and a $\mathrm{Si}_{3} \mathrm{~N}_{4}$ ball with a diameter of $3 \mathrm{~mm}$ was used as the stationary upper counterpart. Each experiment was repeated three times to determine a mean value. The morphologies of the worn surface were observed by SEM (FEI Quanta FEG 250) and 3D laser scanning confocal microscopy (LSCM; Keyence model VK$\mathrm{X} 200 \mathrm{~K})$. To evaluate the corrosion resistance of the coatings, the samples were immersed in $3.5 \% \mathrm{NaCl}$ solution for $40 \mathrm{~d}$, and then the EIS (CHI-660) and Tafel plots were measured. Electrochemical data were collected using a ModuLab electrochemical workstation (Solartron) equipped with a typical three-electrode device, including the reference electrode (saturated calomel electrode (SCE)), counter electrode (platinum plate with $2.5 \mathrm{~cm}^{2}$ area), and working electrode. Impedance measurements were recorded in the frequency range of $100 \mathrm{kHz}$ to $0.01 \mathrm{~Hz}$ using an alternating current signal with an amplitude of $10 \mathrm{mV}$. Potentiodynamic polarization tests were performed with the value of the open circuit potential (Eocp) of $\pm 250 \mathrm{mV}$ and a sweep rate of $1 \mathrm{mV} / \mathrm{s}$.

\section{Results and discussion}

\subsection{Morphology and particle size analysis}

A micrometer laser particle size analyzer is suitable for the measurement of microparticles, but there is a large error in the measurement of nanoparticles. Dynamic light-scattering particle size analyzers are only suitable for the measurement of nanoparticles. The shape of the MCBN/NCBN particles was irregular, as shown in Fig. 1. It is obvious that the mean diameter of the micro-CBN particles was approximately $5 \mu \mathrm{m}$, and the NCBN particle diameter was approximately $550 \mathrm{~nm}$ according to the size distribution.

\subsection{Surface modification}

The non-covalently bonded dopamine molecules experienced alkaline induced $\mathrm{pH}$-oxidation and further nucleophilic reaction associated with rearrangement, followed by dopamine self-polymerization on the surface of the CBN particles [22-26]. The optical image
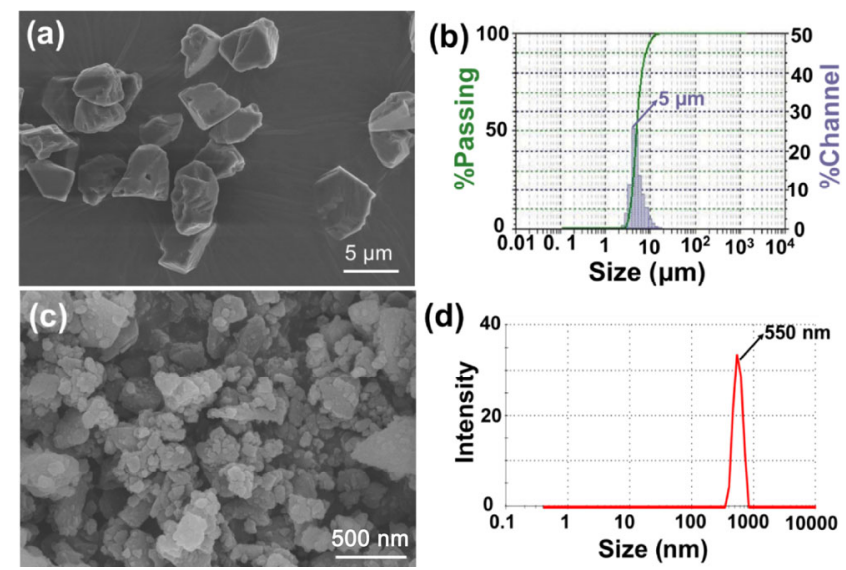

Fig. 1 SEM image (a) and size distribution (b) of micro-CBN particles; SEM image (c) and size distribution (d) of NCBN particles.

of CBN dissolved in xylene solution of EP for $2 \mathrm{~d}$ is shown in Figs. 2(a) and 2(b). The EP dispersion of dopamine-treated CBN particles showed a darker color, which indirectly indicated that the dopamine was successfully grafted onto the surface of the CBN. After allowing the EP dispersion of xylene to stand for $2 \mathrm{~d}$, we could clearly see that the EP dispersions of unmodified CBN particles showed obvious delamination and many CBN particles at the bottom of sample bottle. However, there was no obvious delamination or precipitation in the EP dispersions of the PDA-modified CBN particles. This indicated that modification by PDA directly enhanced the compatibility of CBN in EP.

High-resolution TEM images confirmed the successful noncovalent functionalization of $\mathrm{CBN}$ particles by PDA. The images in Figs. 2(c) and 2(d) clearly reveal that there was a thin layer of PDA with a thickness of 5-6 nm and 4-5 nm on the surface of the MCBN and NCBN particles, respectively. The energy dispersive spectrometer showed that a considerable amount of carbon and oxygen appeared on the CBN surface in Figs. 2(e)-2(h). This further proved that dopamine was successfully grafted onto the surface of the CBN particles.

The surface chemical composition was further confirmed by Raman spectra, as shown in Fig. 3(a). The Raman shifts at 1,035 and 1,287 $\mathrm{cm}^{-1}$ correspond to the characteristic peaks of CBN. A new peak at $1,580 \mathrm{~cm}^{-1}$ appeared after modification, and was assigned to the stretching vibration and deformation of catechol in the PDA structure [27, 28]. 


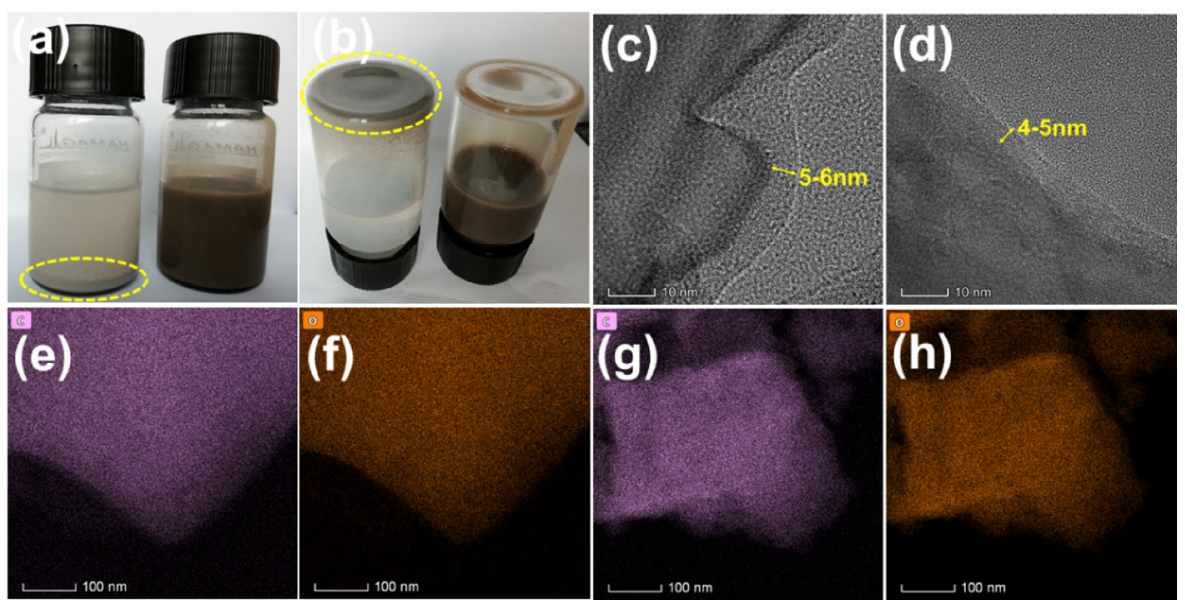

Fig. 2 Optical images of CBN dissolved in xylene solution of epoxy resin for $2 \mathrm{~d}(\mathrm{a}, \mathrm{b})$. TEM images of MCBN (c) and of NCBN (d). EDS spectrum of MCBN $(e, f)$ and of $\operatorname{NCBN}(g, h)$.
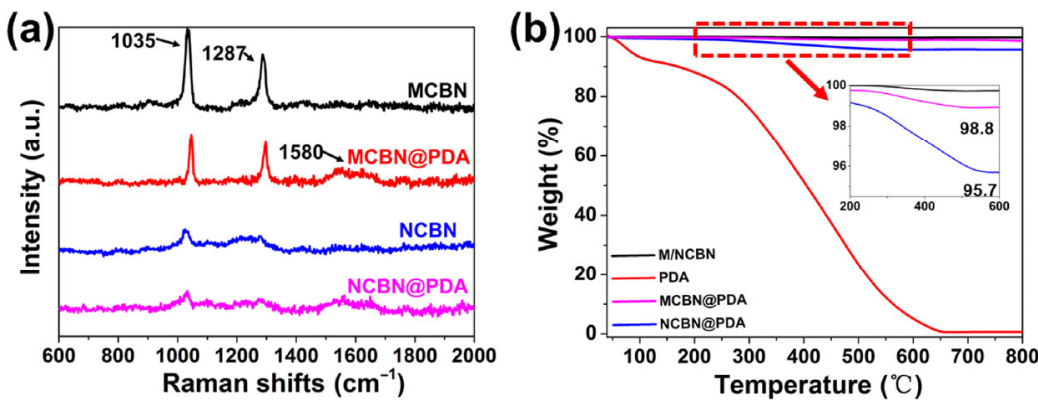

Fig. 3 Raman spectra of MCBN and NCBN (a), and TGA of PDA, MCBN@PDA, and NCBN@PDA (b).

Figure 3(b) compared the thermal degradation behaviors of pristine and functionalized CBN particles. Pristine CBN exhibited high thermal stability up to $800{ }^{\circ} \mathrm{C}$ without causing any decomposition. On the other hand, the dopamine-treated nanoparticles began to degrade at approximately $200{ }^{\circ} \mathrm{C}$ and then experienced major weight loss between 250 to $550{ }^{\circ} \mathrm{C}$, which corresponded to the decomposition of PDA molecules attached to the surface of the CBN micro/ nanoparticles. In addition, approximately $4.3 \%$ and $1.2 \%$ PDA were noncovalently attached to the MCBN and NCBN particles, respectively.

\subsection{Mechanical and thermal properties of CBN composite coating}

Hardness had an important influence on the load carrying capacity of the composite coatings. The Vickers hardness of composite coatings for the different ratios of MCBN/NCBN particles is shown in Fig. 4(a). It was observed that the hardness of the composite coatings decreased along with the content of micro-CBN (the coating CBN-EP-1 exhibited the highest hardness, which was as high as $19.80 \mathrm{HV}$, increased by $98.0 \%$ compared with $10 \mathrm{HV}$ of neat EP. The coating CBNEP-4 showed the lowest hardness as low as $13.76 \mathrm{HV}$, which represents an increase of $37.6 \%$ compared with neat $\mathrm{EP})$. The relationship between the hardness and the content of micro-CBN was attributed to the excellent load carrying capability of MCBN particles in the composite. The pencil hardness of EP, CBN-EP-1, CBN-EP-2, CBN-EP-3, CBN-EP-4, and CBN-EP-5 was measured as 2, 5, 5, 4, 4, and $4 \mathrm{H}$, respectively, generally consistent with the Vickers hardness. The difference in the hardness of the CBN-EP composite coatings was mainly due to the fact that the MCBN particles were more effective in increasing the coatings' hardness.

The mechanical properties also had a considerable impact on the tribological properties. The tensile stress and elongation at break of the CBN composite coatings and pure EP are shown in Fig. 4(b). The tensile stress of the CBN composite coatings shows a $20 \%-30 \%$ 

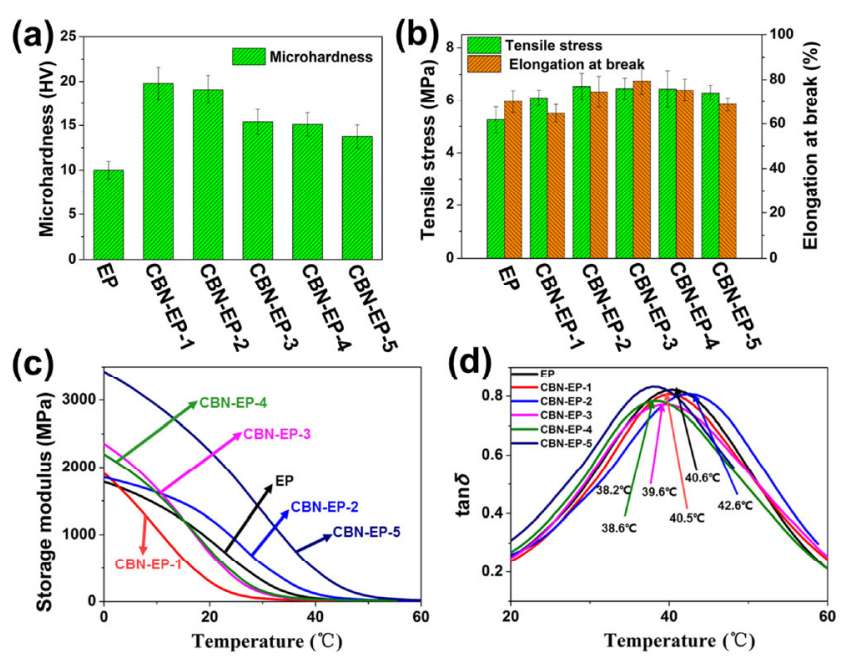

Fig. 4 Microhardness (a), tensile strength and elongation at break (b), storage modulus (c), and $\tan \delta$ (d) of pure EP and CBN-EP composite coatings

increase compared with pure EP, and the elongation at break decreased, except for the CBN-EP-1 coating. We can conclude that the incorporation of $\mathrm{CBN}$ in EP maintained its relative toughness, while enhancing the mechanical strength of EP.

Due to the large amount of heat generated during the friction process, the change in mechanical properties according to the change in temperature, and the glass-transition temperature of the composite coatings are of great significance. The DMA technique was used to investigate the characteristic dynamic mechanical parameters of the CBN-EP composite coatings. The results shown in Figs. 4(c) and 4(d) prove that the storage modulus of the composite coatings containing only MCBN particles (CBN-EP-1) decreased greatly, and the storage modulus of the composite coatings containing only NCBN particles (CBN-EP-5) increased substantially. However, the composite coatings containing both MCBN and NCBN (CBN-EP-2, CBN-EP-3, CBN-EP-4) showed relatively little change. The storage modulus decreased significantly above $10^{\circ} \mathrm{C}$, which was ascribed to the need for the molecular chains to dissipate energy in order to overcome viscous motion. Correspondingly, as displayed in Fig. 4(d), the glasstransition temperature $\left(T_{\mathrm{g}}\right)$ of the composite coatings CBN-EP-1, CBN-EP-3, CBN-EP-4, and CBN-EP-5 decreased in contrast with pure $\mathrm{EP}$, which was attributed to the addition of micro/nano-CBN particles being beneficial to the movement of polymer chains. However, $T_{g}$ of the composite coating of CBN-EP-2 increased, which may have been due to its more compact structure.

The fracture surface images of pure EP and CBN-EP composites were investigated by SEM to further analyze the mechanical properties and are shown in Fig. 5. The cross-sections of CBN-EP composite coatings and pure EP were derived from brittle fracture under liquid nitrogen conditions. The fractured surface morphology of the pure EP was smooth (Fig. 5(a)), which corresponded to typical brittle fracture behavior. Compared with pure EP, more obvious plastic deformations were presented on the composite coatings, which were due to a large number of vein patterns formed on the fractured surface $[3,29]$. The number of vein patterns on the EP composite coatings with more MCBN particles (CBN-EP-1, CBN-EP-2, CBN-EP-3) was lower than on the composite coatings with more NCBN particles (CBN-EP-4, CBN-EP-5). It was indicated that NCBN particles are more likely to improve the composite coating's plasticity.

\subsection{Tribological properties}

To determine the suitable filler ratio of CBN with various particle sizes added to EP for the best tribological performance under different operating conditions, the coefficient of friction (COF) and wear rate of the $\mathrm{CBN}$-EP composite coatings are investigated in this section. In addition, to elaborate the different effects of CBN particles of different sizes on the tribological properties of EP composite coatings, the wear track of the coatings was also detected.

Figures 6(a) and 6(c) shows the COF and wear rate of pure EP and CBN-EP composite coatings under dry sliding conditions. It can be observed that the COF increased quickly in the first stage, and then gradually reached a stable state. Moreover, the results indicated that the COF of the five ratios of EP composite coatings were basically the same, and it decreased by approximately $25 \%$ compared with pure EP in dry sliding conditions. Figure 6(c) shows the wear rate of neat EP and EP composite coatings with different proportions of MCBN and NCBN particles under dry sliding conditions. It can be observed that the wear rate of EP composite coatings decreases drastically, which indicates that the presence of CBN particles can significantly improve the wear resistance of the 


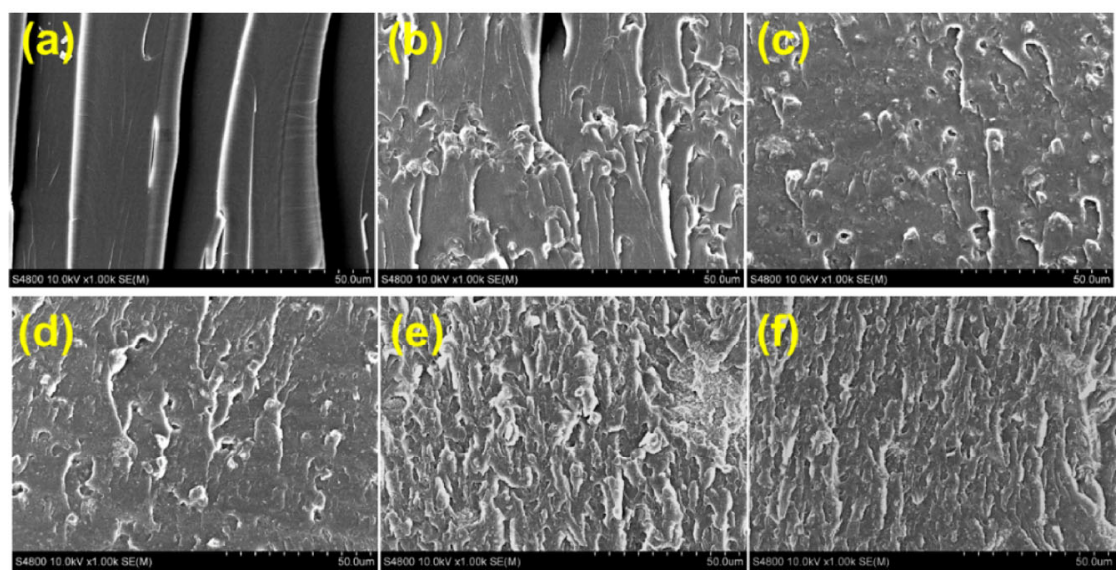

Fig. 5 SEM images of fractured surface morphologies of pure EP (a), CBN-EP-1 (b), CBN-EP-2 (c), CBN-EP-3 (d), CBN-EP-4 (e), and CBN-EP-5 (f).

composite coatings. Moreover, the optimal addition of MCBN and NCBN in EP for the lowest wear rate value was 15 and $15 \mathrm{wt} \%$. The wear rate of CBN-EP-3 was as low as $10.50 \times 10^{-5} \mathrm{~mm}^{-3} \cdot \mathrm{N}^{-1} \cdot \mathrm{m}^{-1}$, which is only $79.45 \%$ less than the neat EP coating $\left(51.10 \times 10^{-5} \mathrm{~mm}^{-3} \cdot \mathrm{N}^{-1} \cdot \mathrm{m}^{-1}\right)$ under dry sliding conditions.

The trend of the COF and wear rate of coatings series presented above was ascribed to the following: The neat EP exhibited a typical brittle feature, and was prone to producing long cracks when in mechanical contacted with the rigid friction pair, resulting in higher COF. A slight decrease in the COF of the composite coatings could be attributed to the promotion of hardness and toughness in the composite coatings, which reduced the expansion of cracks and formed a smooth surface with little wear debris [3, 30].

Figure $6(\mathrm{~b})$ shows the COF of pure EP and CBN-EP composite coatings under seawater conditions. The tendency of the COF under seawater conditions is the same as under dry sliding conditions, where it increased rapidly and then stabilized. Moreover, the results indicate that the COF of the five ratios of EP composite coatings decreases drastically and is positively correlated with hardness.

Figure 6(d) shows the wear rate of neat EP and EP composite coatings with different proportions of MCBN and NCBN under seawater conditions. It can be observed that the wear rate of EP composite coatings reduced in order of magnitude, which was attributed to lubrication with water and the natural lubrication of EP. Furthermore, the optimal ratio of MCBN and NCBN for the lowest wear rate was $20 \mathrm{wt} \%$ and
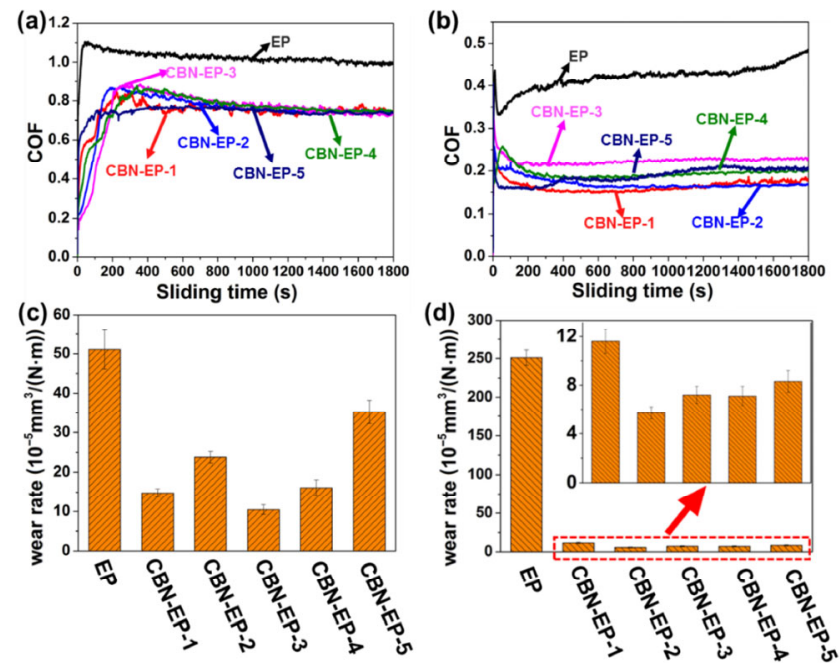

Fig. 6 Tribological properties of EP and CBN-EP composite coatings under dry sliding conditions (load: $5 \mathrm{~N}$, sliding frequency: $5 \mathrm{~Hz}$ ) and seawater lubrication conditions (load: $10 \mathrm{~N}$, sliding frequency: $5 \mathrm{~Hz}$ ); friction coefficients under dry sliding conditions (a) and under seawater conditions (b); wear rate under dry sliding conditions (c) and under seawater conditions (d).

$10 \mathrm{wt} \%$, in which CBN-EP-3 displayed the highest hardness. The wear rate of CBN-EP-3 was as low as $5.70 \times 10^{-5} \mathrm{~mm}^{-3} \cdot \mathrm{N}^{-1} \cdot \mathrm{m}^{-1}, 97.81 \%$ lower than the neat EP coating $\left(251.20 \times 10^{-5} \mathrm{~mm}^{-3} \cdot \mathrm{N}^{-1} \cdot \mathrm{m}^{-1}\right)$ under seawater conditions.

The trend presented above was ascribed to the following: the lubricating effect of seawater can reduce direct contact between the friction ball and the surface of the coating. However, frictional heat and wear debris can be removed by seawater continuously during sliding, which results in a cold, clean, and smooth counterpart surface to some extent [31, 32]. However, 
the lubricating effect of seawater does not work, and could not prevent the generation of debris on pure EP. Moreover, the toughness of the CBN-EP composite coatings made the lubrication by seawater more effective, reducing the wear debris peeled from the coatings. The optimal proportion of micro- and nanoparticles in composite coatings was different between the dry and seawater sliding conditions, which may have been due to the different loading conditions.

Furthermore, there were different friction mechanisms under dry sliding and seawater conditions. The fillers concentrate stress and absorb a large number of energy during the friction process [33-35]. In addition, the load-carrying capacity of microsized particles was better than that of nanosized particles. In the dry sliding conditions, the optimal ratios of MCBN and NCBN corresponding to the lowest wear rate value were $15 \mathrm{wt} \%$ and $15 \mathrm{wt} \%$, which was ascribed to the load- carrying capacity of the microsized particles, and the reinforcement of the nanosized particles with the appropriate hardness, tensile strength, storage modulus, and glass transition temperature. However, under seawater conditions, the optimal proportions of microCBN and NCBN for the lowest COF and wear rate was 20 and $10 \mathrm{wt} \%$, which might be attributed to the higher hardness and glass transition temperature.

Figures 7 and 8 show the worn surface morphologies of EP and CBN-EP composite coatings with different proportions of neat EP and CBN-EP composite coatings in both dry sliding and seawater conditions. For the dry sliding condition, the optical images in Fig. 7 show that the wear trace on the EP and CBN-EP composite coatings was not only extremely rough, but also generated more wear debris. For the EP, a large number of cracks can be observed along the edge of the wear trace marked by the red loop in Fig. $7\left(\mathrm{a}_{1}\right)$. Moreover, the

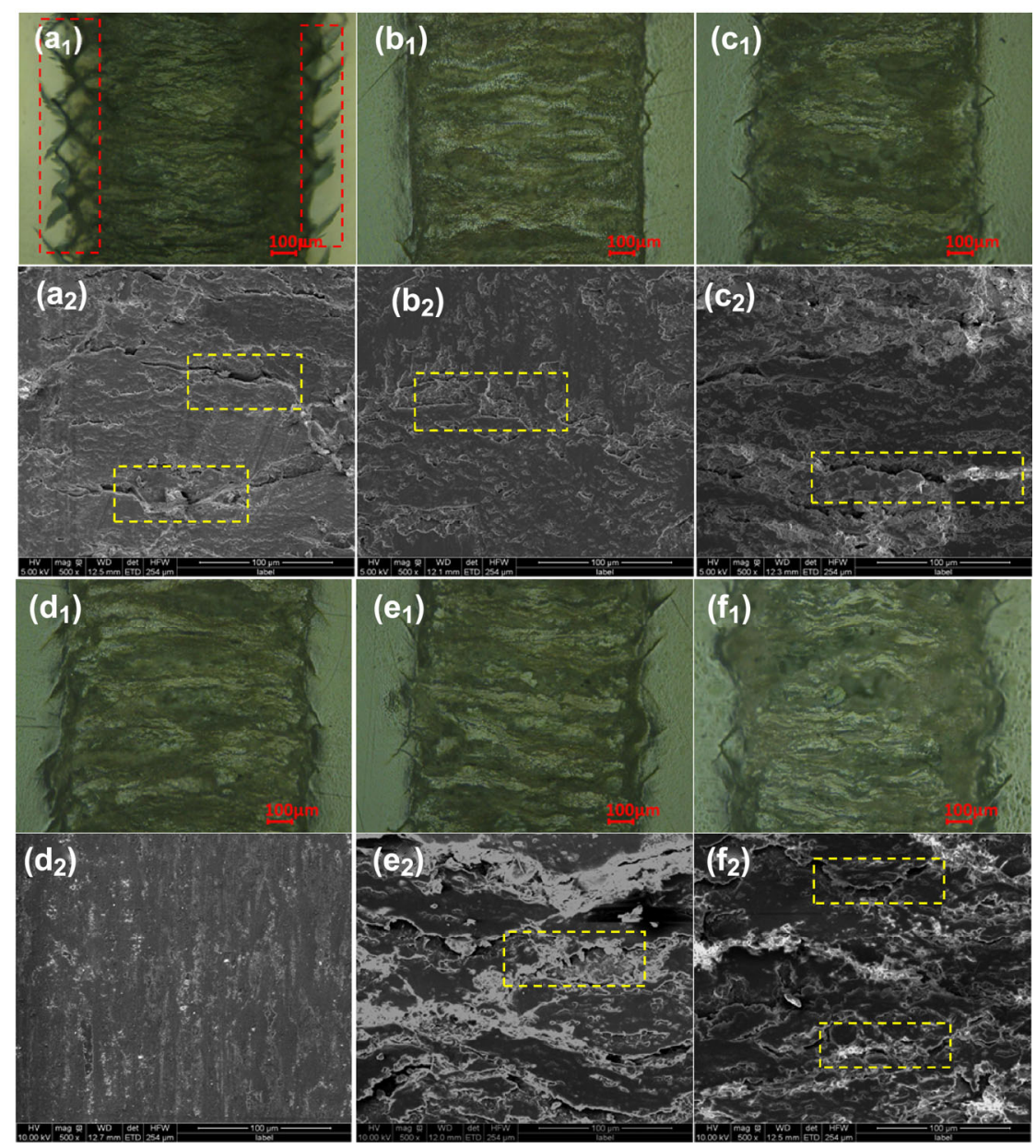

Fig. 7 Optical images and SEM images of worn surface for coatings under dry sliding conditions: pure EP $\left(a_{1}, a_{2}\right), C B N-E P-1\left(b_{1}, b_{2}\right)$, CBN-EP-2 $\left(\mathrm{c}_{1}, \mathrm{c}_{2}\right)$, CBN-EP-3 $\left(\mathrm{d}_{1}, \mathrm{~d}_{2}\right)$, CBN-EP-4 $\left(\mathrm{e}_{1}, \mathrm{e}_{2}\right)$, CBN-EP-5 $\left(\mathrm{f}_{1}, \mathrm{f}_{2}\right)$. 
SEM images in Fig. 7 show a number of microcracks on the wear trace of the neat EP and CBN-EP composite coatings, except for the CBN-EP-2 composite coating in Fig. $7\left(c_{2}\right)$, which did not show any cracks, and these results were consistent with the lowest wear rate. For the seawater conditions, the optical image of neat EP in Fig. 8( $\left.\mathrm{a}_{1}\right)$ not only showed a coarse wear trace, but also many cracks along the wear trace edge marked by a red loop, whereas the optical morphologies of the CBN-EP composite coatings were smoother than in dry sliding conditions, even though the load force of seawater friction was twice that in dry friction conditions. In particular, the wear trace morphology of the optimal proportion of fillers for the CBN-EP-2 composite coating in Fig. 8( $\left.c_{1}\right)$ was the smoothest, which was consistent with the data obtained from the tribological experiments. Moreover, the SEM images in Fig. 8 further revealed the friction process of the coatings. The SEM image of neat EP in Fig. 8( $\left.\mathrm{a}_{2}\right)$ shows serious wear debris peeling, which was attributed to its brittle property. The wear trace of the CBN-EP composite coatings in Fig. $8\left(\mathrm{~b}_{2}\right)$ shows many fragments marked by yellow loops. The wear trace of CBN-EP-2 and CBN-EP-3 composite coatings in Figs. 8( $\left.\mathrm{C}_{2}\right)$ and $8\left(\mathrm{~d}_{2}\right)$ show some superfine debris as friction lubricant, marked by yellow loops. The wear trace of CBN-EP-4 composite coatings in Fig. 8( $\left.\mathrm{e}_{2}\right)$ shows typical fatigue wear. The wear trace of CBN-EP-5 composite coatings show massive debris marked by yellow loops, due to the addition of numerous nanoparticles.

Figure 9 further elaborates the friction mechanism of the neat EP and CBN-EP composite coatings. The addition of micro/nanofillers can inhibit crack generation and expansion. Under dry sliding conditions, cracks were easily generated, and obvious adhesive wear occurred. This was mainly ascribed to the

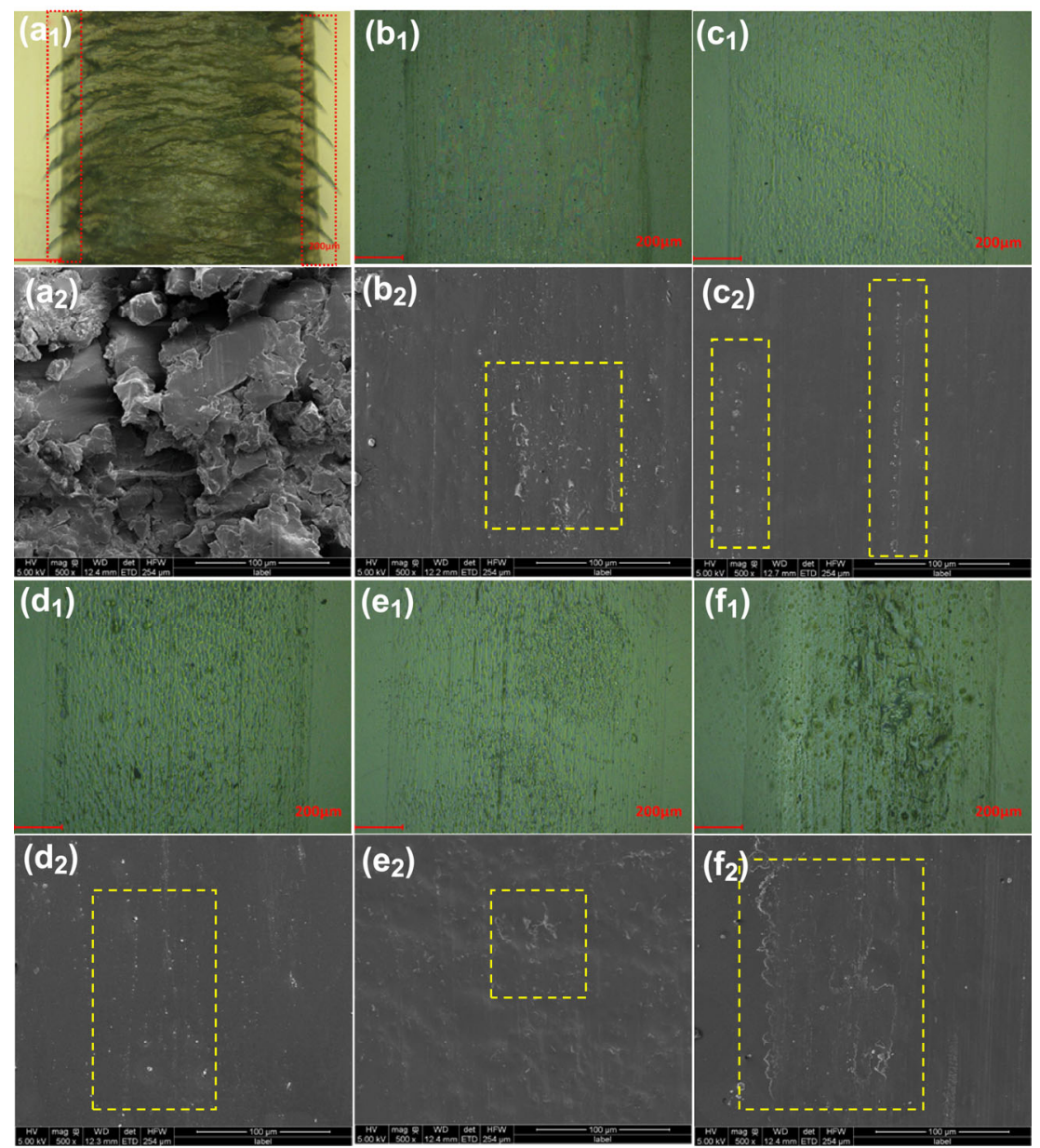

Fig. 8 Optical images and SEM images of worn surface for coatings under seawater conditions: pure EP $\left(a_{1}, a_{2}\right), C B N-E P-1\left(b_{1}, b_{2}\right)$, CBN-EP-2 $\left(\mathrm{c}_{1}, \mathrm{c}_{2}\right)$, CBN-EP-3 $\left(\mathrm{d}_{1}, \mathrm{~d}_{2}\right)$, CBN-EP-4 $\left(\mathrm{e}_{1}, \mathrm{e}_{2}\right)$, CBN-EP-5 $\left(\mathrm{f}_{1}, \mathrm{f}_{2}\right)$. 


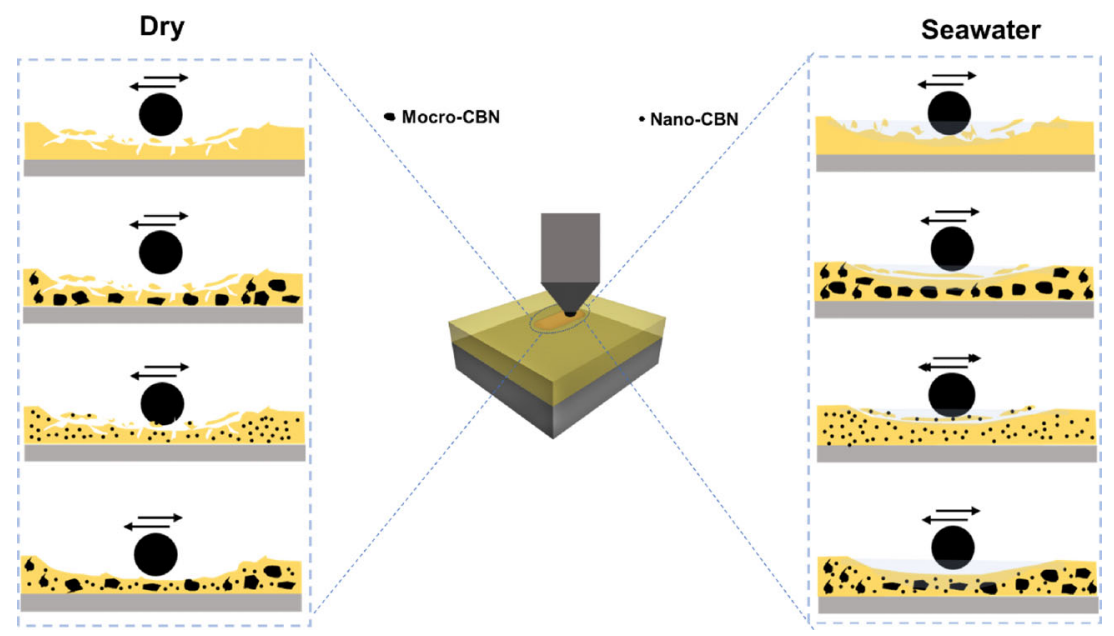

Fig. 9 Schematic of wear mechanism of EP composite coatings enhanced via MCBN and NCBN fillers.

substantial heat generated during the friction process, which caused the temperature of the coating surface to approach the glass transition temperature of the EP in the absence of any external lubrication or cooling condition. However, the addition of filler can reduce the generation of cracks in the coatings, or greatly eliminate cracks in the coating when the proportion of microsized and nanosized CBN particles was $15 \mathrm{wt} \%$ and $15 \mathrm{wt} \%$. At this time, the wear mechanism of the coating changed from crack generation and adhesive wear to fatigue wear. Under seawater conditions, the temperature of the friction surface was close to room temperature. This was attributed to the cooling behavior of seawater, which resulted in lower temperature compared with dry sliding. The EP coating showed typical brittleness, which produced numerous fragments corresponding to its maximum wear rate. However, the CBN-EP composite coatings were free of obvious cracks during the friction process, and showed mainly abrasive wear and fatigue wear attributable to the improvement in the mechanical performance of the composite coatings. Moreover, the debris of the CBN-EP-2 and CBN-EP-3 composite coatings that incorporated a low content nanosized CBN particles was less than the CBN-EP-1 composite coatings that added only microsized CBN particles. When the nanosized particles increased, more debris peeling occurred.

\subsection{Anti-corrosion properties}

In order to evaluate the corrosion resistance of the neat EP and composite coatings reinforced with the CBN particles, Tafel plots of pure EP and CBN-EP composite coatings exposed to $3.5 \mathrm{wt} \% \mathrm{NaCl}$ solution were displayed in Fig. 10. Some important parameters, including current density $\left(I_{\text {corr }}\right)$, corrosion potential $\left(E_{\text {corr }}\right)$ and protection promotion $(\eta)$ derived from the polarization curves are listed in Table 2.

The protection promotion $\eta$ of CBN-EP coatings on the substrate was calculated from the $I_{\text {corr }}$ values

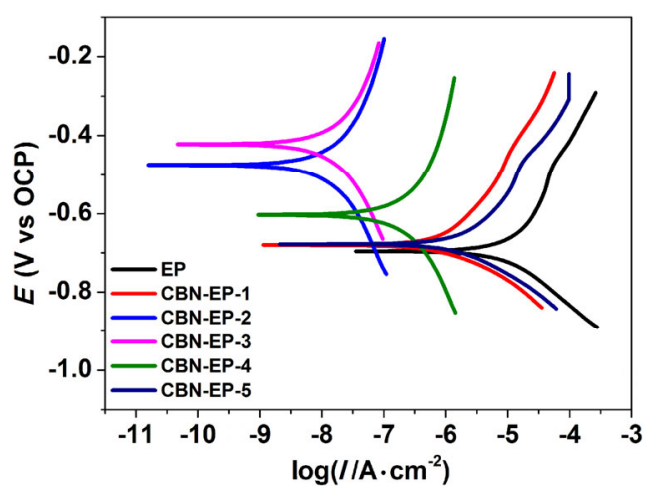

Fig. 10 Polarization plots for the coatings in $3.5 \mathrm{wt} \% \mathrm{NaCl}$.

Table 2 Electrochemical parameters for bare and coated substrates obtained from polarization curves.

\begin{tabular}{cccc}
\hline Samples & $I_{\text {corr }}\left(\mathrm{A} \cdot \mathrm{cm}^{-2}\right)$ & $E_{\text {corr }}(\mathrm{V})$ & $\eta(\%)$ \\
\hline EP & $1.239 \times 10^{-5}$ & -0.6973 & \\
CBN-EP-1 & $9.365 \times 10^{-7}$ & -0.6453 & 92.44 \\
CBN-EP-2 & $1.287 \times 10^{-8}$ & -0.4757 & 99.99 \\
CBN-EP-3 & $1.458 \times 10^{-8}$ & -0.4217 & 99.88 \\
CBN-EP-4 & $2.047 \times 10^{-7}$ & -0.6039 & 98.01 \\
CBN-EP-5 & $1.941 \times 10^{-6}$ & -0.6465 & 84.33 \\
\hline
\end{tabular}


according to the following equation: [36]

$$
\eta=\frac{I_{\text {ep }}-I_{\text {corr }}}{I_{\text {ep }}} \times 100 \%,
$$

where $I_{\mathrm{ep}}$ and $I_{\text {corr }}$ are the corrosion current densities of EP and CBN-EP coatings, respectively.

In general, a lower $I_{\text {corr }}$ value represents a lower corrosion dynamic rate. By comparing the value of $I_{\text {corr }}$ and $\eta$ from different perspectives, two important pieces of information can be obtained. First, the $I_{\text {corr }}$ of the pure EP coating was higher than that of CBN-EP composite coatings. Secondly, the $I_{\text {corr }}$ of the composite coatings reinforced with only LCBN or FCBN particles was higher than that of the composite coatings reinforced with both micro-CBN and NCBN particles. In addition, the optimal ratio of micro-CBN and NCBN corresponding to the lowest $I_{\text {corr }}$ was $20 \mathrm{wt} \%$ and $10 \mathrm{wt} \%$. The large addition of nanosized particles in EP may result in more defects in the composite coatings.

In addition, EIS was used to evaluate anti-corrosion properties [37-42]. Figure 11 presents the Nyquist plane plots and Bode plots of the measurements in the seawater condition. It can be observed that the Nyquist plane plots and the Bode plots show the sequence pure EP $<$ CBN-EP-5 < CBN-EP-1 < CBNEP-3 $<$ CBN-EP-4 $<$ CBN-EP-2. The coating with the highest EIS is CBN-EP-2, which exceeds $10^{7} \Omega \cdot \mathrm{cm}^{-2}$, two orders of magnitude greater than neat EP coating (approximately $10^{5} \Omega \cdot \mathrm{cm}^{-2}$ ). The EIS values of the other four composite coatings are close to $10^{7} \Omega \cdot \mathrm{cm}^{-2}$. The obtained results are consistent with the tendency of the polarization curves. The obtained curves were fitted with electrochemical equivalent circuits and are shown in Fig. 11. The equivalent circuits contained elements corresponding to the solution resistance $\left(R_{\mathrm{s}}\right)$, double layer capacitance $\left(Q_{\mathrm{dl}}\right)$, charge transfer resistance $\left(R_{\mathrm{ct}}\right)$, coating capacitance $\left(Q_{\text {film }}\right)$, and coating resistance $\left(R_{\text {film }}\right)[38,43,44]$. The measured impedance approached the sum of $R_{\mathrm{ct}}$ and $R_{\mathrm{film}}$ at the low frequency end $\left(R_{\mathrm{p}}=R_{\mathrm{film}}+R_{\mathrm{ct}}\right)$. The equivalent circuit description for the $\mathrm{EP}$ and composite coatings is $\mathrm{R}(\mathrm{QR})(\mathrm{QR})$. The values of the impedance parameters are listed in Table 3. The values of $R_{\mathrm{ct}}$ and $R_{\text {film }}$ for the composite coatings are correspondingly improved compared with pure EP coating, which mean the increase of the EIS for the composite coatings. The $R_{\mathrm{p}}$ value obtained for the coatings varies from $2.42 \times 10^{5}(\mathrm{EP})$ to $1.61 \times 10^{7} \Omega \cdot \mathrm{cm}^{-2}$ (CBN-EP-2). Slightly higher $R_{\mathrm{p}}$ values were obtained for the composite coatings than the pure EP coating, indicating improved corrosion resistance.

Generally, many micropores may naturally exist in the matrix, which makes it easier for a corrosion medium to penetrate. Furthermore, the addition of CBN particles may block the defects formed in the EP coating, resulting in the formation of a compact structure [45]. According to the above results, an anti-corrosion mechanism was illustrated in Fig. 12. As the nanosized CBN particle content increased, the
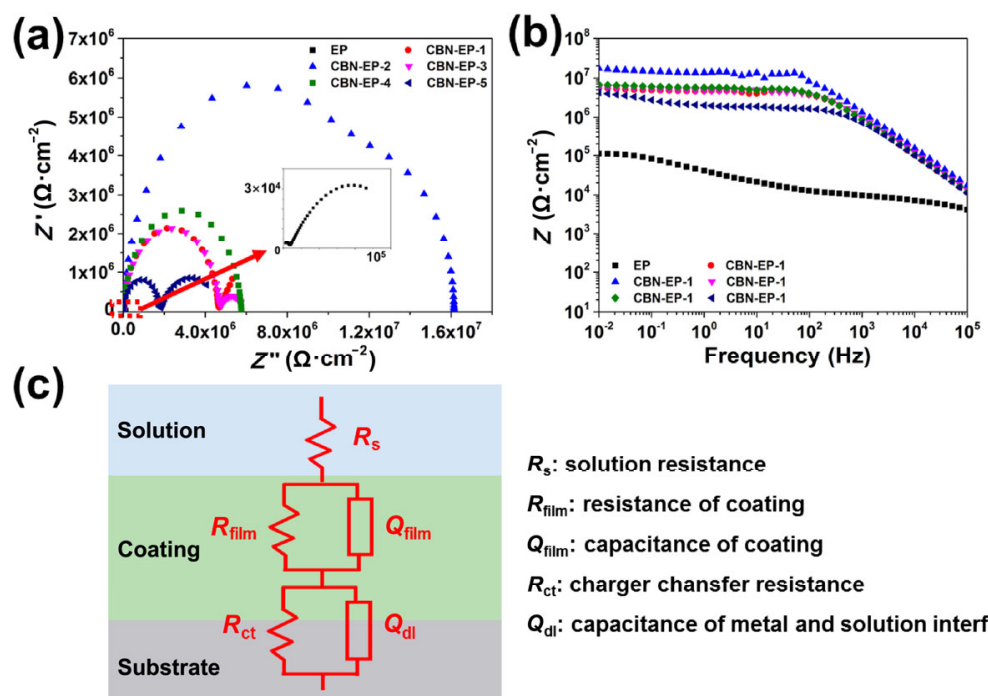
$\boldsymbol{R}_{\mathbf{s}}$ : solution resistance
$\boldsymbol{R}_{\text {film: }}$ resistance of coating
$Q_{\text {film: }}$ : capacitance of coating
$\boldsymbol{R}_{\mathrm{ct}}$ : charger chansfer resistance
$Q_{\mathrm{dll}}$ : capacitance of metal and solution interface

Fig. 11 Nyquist plots (a), Bode plots (b), and the equivalent electrical circuits for impedance measurements (c). 
Table 3 EIS parameters corresponding to the equivalent circuit for six coatings.

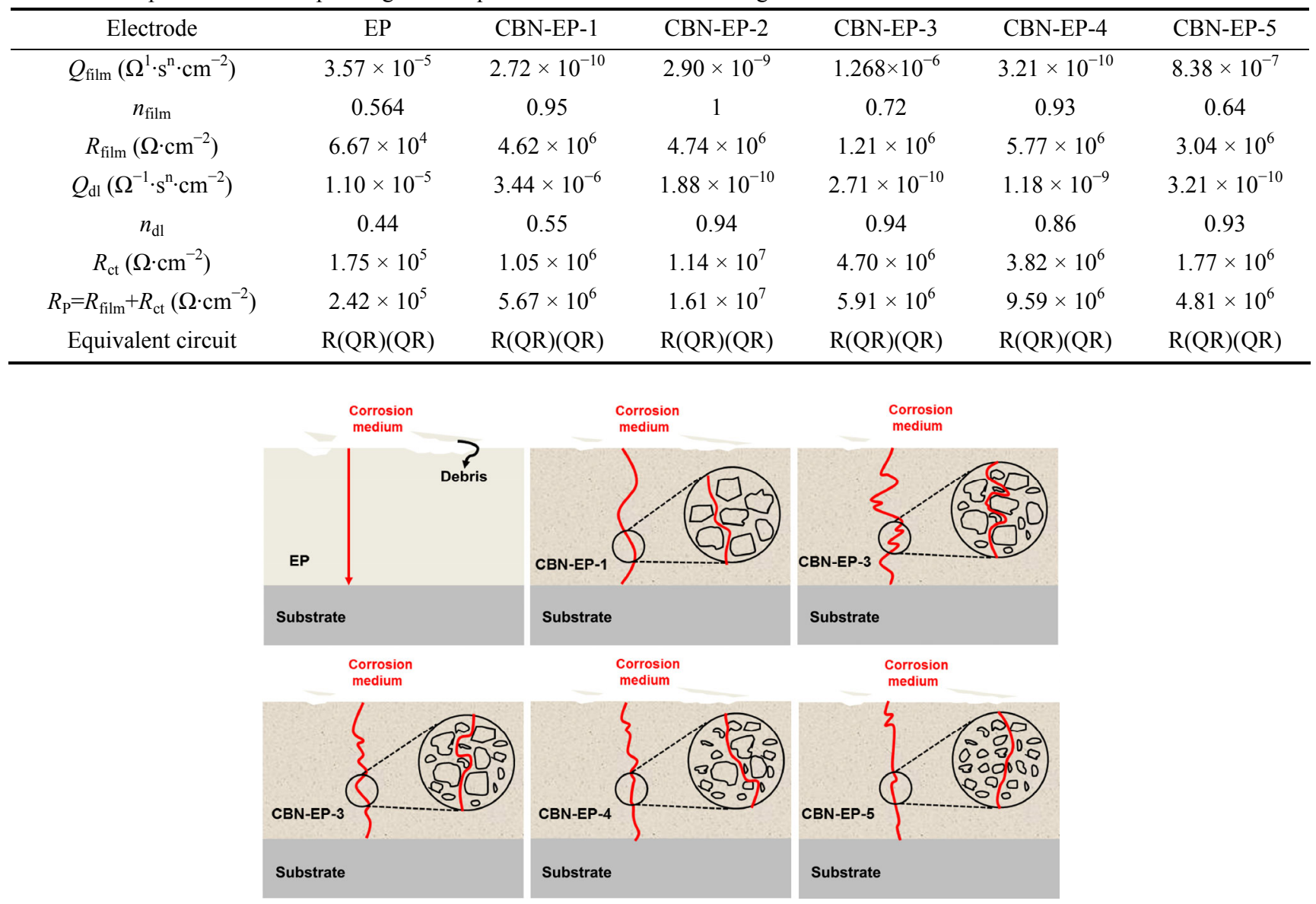

Fig. 12 Anti-corrosion mechanisms of pure EP and CBN-EP composite coatings.

nanosized CBN particles easily occupied the space between the microparticles. In this way, the CBN particles began to come into contact with each other and form a more compact packing structure, thereby exhibiting better barrier and anti-corrosion properties.

\section{Conclusions}

In summary, the EP and EP composite coatings reinforced by a high content (30 wt $\%$ ) of CBN particles with microsized and nanosized particles were successfully prepared, and various characterization methods were used to evaluate their tribological behaviors and anti-corrosion properties. The dispersibility and compatibility of CBN particles in EP can be greatly improved by PDA modification. CBN-EP composite coatings showed significantly improved mechanical properties, especially hardness. The friction and corrosion resistance of the composite coatings were greatly improved. When the additive proportions of MCBN and NCBN particles was 1:1, the tribological performance of EP composite coatings was optimal under dry sliding conditions. When the additive proportion of MCBN and NCBN particles was 2:1, the tribological and corrosion resistance performance was optimal in seawater conditions. We ascribed this to the more compact structure, which improved the mechanical properties and electrolyte barrier of the composite coatings. The addition of microsized CBN particles enabled the composite coating to possess better load-carrying capability, while the addition of nanosized particles improved the toughness of the coating.

\section{Acknowledgements}

We express our great thanks to the National Natural Science Foundation of China (No. 51775540), Key 
Research Program of Frontier Sciences of the Chinese Academy of Science (No. QYZDY-SSW-JSC009), and the Youth Innovation Promotion Association, CAS (No. 2017338).

Open Access: This article is licensed under a Creative Commons Attribution 4.0 International License, which permits use, sharing, adaptation, distribution and reproduction in any medium or format, as long as you give appropriate credit to the original author(s) and the source, provide a link to the Creative Commons licence, and indicate if changes were made.

The images or other third party material in this article are included in the article's Creative Commons licence, unless indicated otherwise in a credit line to the material. If material is not included in the article's Creative Commons licence and your intended use is not permitted by statutory regulation or exceeds the permitted use, you will need to obtain permission directly from the copyright holder.

To view a copy of this licence, visit http://creativecommons.org/licenses/by/4.0/.

\section{References}

[1] Wang N, Cheng K Q, Wu H, Wang C, Wang Q C, Wang F H. Effect of nano-sized mesoporous silica MCM-41 and MMT on corrosion properties of epoxy coating. Prog Org Coat 75(4): 386-391 (2012)

[2] Yan L, Wang H Y, Wang C, Sun L Y, Liu D J, Zhu Y J. Friction and wear properties of aligned carbon nanotubes reinforced epoxy composites under water lubricated condition. Wear 308(1-2): 105-112 (2013)

[3] Yu J J, Zhao W J, Wu Y H, Wang D L, Feng R T. Tribological properties of epoxy composite coatings reinforced with functionalized C-BN and H-BN nanofillers. Appl Surf Sci 434: 1311-1320 (2018)

[4] Chang L, Zhang Z, Ye L, Friedrich K. Tribological properties of epoxy nanocomposites: III. Characteristics of transfer films. Wear 262(5-6): 699-706 (2007)

[5] Wetzel B, Haupert F, Zhang M Q. Epoxy nanocomposites with high mechanical and tribological performance. Comp Sci Technol 63(14): 2055-2067 (2003)

[6] Neitzel I, Mochalin V, Bares J A, Carpick R W, Erdemir A, Gogotsi Y. Tribological properties of nanodiamond-epoxy composites. Tribol Lett 47(2): 195-202 (2012)

[7] Wang Z Z, Gu P, Wu X P, Zhang H, Zhang Z, Chiang M Y
M. Micro/nano-wear studies on epoxy/silica nanocomposites. Comp Sci Technol 79: 49-57 (2013)

[8] Shen X J, Pei X Q, Fu S Y, Friedrich K. Significantly modified tribological performance of epoxy nanocomposites at very low graphene oxide content. Polymer 54(3): 1234-1242 (2013)

[9] Cui L J, Geng H Z, Wang W Y, Chen L T, Gao J. Functionalization of multi-wall carbon nanotubes to reduce the coefficient of the friction and improve the wear resistance of multi-wall carbon nanotube/epoxy composites. Carbon 54: 277-282 (2013)

[10] Jiang F W, Zhao W J, Wu Y M, Wu Y H, Liu G, Dong J D, Zhou K H. A polyethyleneimine-grafted graphene oxide hybrid nanomaterial: Synthesis and anti-corrosion applications. Appl Surf Sci 479: 963-973 (2019)

[11] Shi H W, Liu F C, Yang L H, Han E H. Characterization of protective performance of epoxy reinforced with nanometersized $\mathrm{TiO}_{2}$ and $\mathrm{SiO}_{2}$. Prog Org Coat 62(4): 359-368 (2008)

[12] Fu S Y, Feng X Q, Lauke B, Mai Y W. Effects of particle size, particle/matrix interface adhesion and particle loading on mechanical properties of particulate-polymer composites. Comp Part B: Eng 39(6): 933-961 (2008)

[13] Cho J, Joshi M S, Sun C T. Effect of inclusion size on mechanical properties of polymeric composites with micro and nano particles. Comp Sci Technol 66(13): 1941-1952 (2006)

[14] Singh R P, Zhang M, Chan D. Toughening of a brittle thermosetting polymer: Effects of reinforcement particle size and volume fraction. J Mater Sci 37(4): 781-788 (2002)

[15] Barmouz M, Asadi P, Givi M K B, Taherishargh M. Investigation of mechanical properties of $\mathrm{Cu} / \mathrm{SiC}$ composite fabricated by FSP: Effect of SiC particles' size and volume fraction. Mater Sci Eng: A 528(3): 1740-1749 (2011)

[16] Li W, Tian H, Hou B. Corrosion performance of epoxy coatings modified by nanoparticulate $\mathrm{SiO}_{2}$. Mater Corros 63(1): 44-53 (2012)

[17] Mostafaei A, Nasirpouri F. Epoxy/polyaniline-ZnO nanorods hybrid nanocomposite coatings: Synthesis, characterization and corrosion protection performance of conducting paints. Prog Org Coat 77(1): 146-159 (2014)

[18] Monteiro S N, Skury A L D, de Azevedo M G, Bobrovnitchii G S. Cubic boron nitride competing with diamond as a superhard engineering material-An overview. J Mater Res Technol 2(1): 68-74 (2013)

[19] Semenic T, Hu J, Kraemer S, Housley R, Sudre O. High hardness cubic boron nitride with nanograin microstructure produced by high-energy milling. J Am Ceram Soc 101(10): 4791-4801 (2018)

[20] Tian Y J, Xu B, Yu D L, Ma Y M, Wang Y B, Jiang Y B, 
Hu W T, Tang C C, Gao Y F, Luo K, et al. Ultrahard nanotwinned cubic boron nitride. Nature 493(7432): 385-388 (2013)

[21] Wang Z D, Liu J Y, Cheng Y H, Chen S Y, Yang M M, Huang J L, Wang H K, Wu G L, Wu H J. Alignment of boron nitride nanofibers in epoxy composite films for thermal conductivity and dielectric breakdown strength improvement. Nanomaterials 8(4): 242 (2018)

[22] Hu H Y, Yu B, Ye Q, Gu Y S, Zhou F. Modification of carbon nanotubes with a nanothin polydopamine layer and polydimethylamino-ethyl methacrylate brushes. Carbon 48(8): 2347-2353 (2010)

[23] Liu Q, Wang N Y, Caro J, Huang A S. Bio-inspired polydopamine: A versatile and powerful platform for covalent synthesis of molecular sieve membranes. $\mathrm{J} \mathrm{Am} \mathrm{Chem} \mathrm{Soc}$ 135(47): 17679-17682 (2013)

[24] Ou J F, Wang J Q, Liu S, Zhou J F, Ren S L, Yang S R. Microtribological and electrochemical corrosion behaviors of polydopamine coating on APTS-SAM modified Si substrate. Appl Surf Sci 256(3): 894-899 (2009)

[25] Shen H, Guo J, Wang H, Zhao N, Xu J. Bioinspired modification of h-BN for high thermal conductive composite films with aligned structure. ACS Appl Mater Interfaces 7(10): 5701-5708 (2015)

[26] Wu H C, Kessler M R. Multifunctional cyanate ester nanocomposites reinforced by hexagonal boron nitride after noncovalent biomimetic functionalization. ACS Appl Mater Interfaces 7(10): 5915-5926 (2015)

[27] Ku S H, Lee J S, Chan B P. Spatial control of cell adhesion and patterning through mussel-inspired surface modification by polydopamine. Langmuir 26(19): 15104-15108 (2010)

[28] Shalev T, Gopin A, Bauer M, Stark R W, Rahimipour S. Non-leaching antimicrobial surfaces through polydopamine bio-inspired coating of quaternary ammonium salts or an ultrashort antimicrobial lipopeptide. J Mater Chem 22(5): 2026-2032 (2012)

[29] Ye X Y, Gong P W, Wang J Q, Wang H G, Ren S L, Yang $S$ R. Fluorinated graphene reinforced polyimide films with the improved thermal and mechanical properties. Comp Part A: Appl Sci Manuf 75: 96-103 (2015)

[30] Fei J, Luo W, Huang J F, Ouyang H B, Xu Z W, Yao C Y. Effect of carbon fiber content on the friction and wear performance of paper-based friction materials. Tribol Int $\mathbf{8 7}$ : 91-97 (2015)

[31] Correa C E, Betancourt S, Vázquez A, Gañan P. Wear resistance and friction behavior of thermoset matrix reinforced with Musaceae fiber bundles. Tribol Int 87: 57-64 (2015)

[32] Hvizdoš P, Dusza J, Balázsi C. Tribological properties of $\mathrm{Si}_{3} \mathrm{~N}_{4}$-graphene nanocomposites. J Eur Ceram Soc 33(12):
2359-2364 (2013)

[33] Miyake S, Watanabe S, Murakawa M, Kaneko R, Miyato T. Tribological study of cubic boron nitride film. Thin Solid Films 212(1-2): 262-266 (1992)

[34] Pawlak Z, Kaldonski T, Pai R, Bayraktar E, Oloyede A. A comparative study on the tribological behaviour of hexagonal boron nitride (h-BN) as lubricating micro-particles-An additive in porous sliding bearings for a car clutch. Wear 267(5-8): 1198-1202 (2009)

[35] Liu H, Li Y Q, Wang Y M, Wang Q H. In situ synthesis and thermal, tribological properties of thermosetting polyimide/ graphene oxide nanocomposites. J Mater Sci 47(4): 1867-1874 (2012)

[36] Banerjee S, Mishra A, Singh M M, Maiti B, Ray B, Maiti P. Highly efficient polyurethane ionomer corrosion inhibitor: The effect of chain structure. Rsc Adv 1(2): 199-210 (2011)

[37] Hayatdavoudi H, Rahsepar M. A mechanistic study of the enhanced cathodic protection performance of graphenereinforced zinc rich nanocomposite coating for corrosion protection of carbon steel substrate. J Alloys Compd 727: 1148-1156 (2017)

[38] Yu J J, Zhao W J, Wu Y H, Wu Y M, Wang D L. Anticorrosion mechanism of two-dimensional nanosheet materials in waterborne epoxy coatings. Surf Topogr: Metrol Propert

[39] Shreepathi S, Bajaj P, Mallik B P. Electrochemical impedance spectroscopy investigations of epoxy zinc rich coatings: Role of $\mathrm{Zn}$ content on corrosion protection mechanism. Electrochim Acta 55(18): 5129-5134 (2010)

[40] Chang C H, Huang T C, Peng C W, Yeh T C, Lu H I, Hung W I, Weng C J, Yang T I, Yeh J M. Novel anticorrosion coatings prepared from polyaniline/graphene composites. Carbon 50(14): 5044-5051 (2012)

[41] Chang K C, Hsu M H, Lu H I, Lai M C, Liu P J, Hsu C H, Ji W F, Chuang T L, Wei Y, Yeh J M, et al. Room-temperature cured hydrophobic epoxy/graphene composites as corrosion inhibitor for cold-rolled steel. Carbon 66(2): 144-153(2014)

[42] Qiu S H, Liu G, Li W, Zhao H C, Wang L P. Noncovalent exfoliation of graphene and its multifunctional composite coating with enhanced anticorrosion and tribological performance. J Alloys Compd 747: 60-70 (2018)

[43] Kumar C M P, Venkatesha T V, Shabadi R. Preparation and corrosion behavior of $\mathrm{Ni}$ and $\mathrm{Ni}$-graphene composite coatings. Mater Res Bull 48(4): 1477-1483 (2013)

[44] Balaraju J N, Selvi V E, Rajam K S. Electrochemical behavior of low phosphorus electroless $\mathrm{Ni}-\mathrm{P}-\mathrm{Si}_{3} \mathrm{~N}_{4}$ composite coatings. Mater Chem Phys 120(2-3): 546-551 (2010)

[45] Selvakumar N, Jeyasubramanian K, Sharmila R. Smart coating for corrosion protection by adopting nano particles. Prog Org Coat 74(3): 461-469 (2012) 


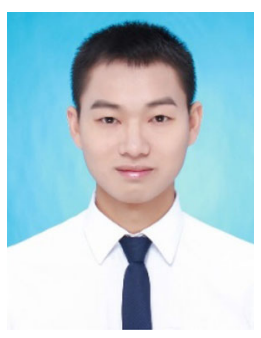

Zhiping HUANG. He received his bachelor degree in polymer materials and engineering in 2013 from Nanchang Hangkong University,

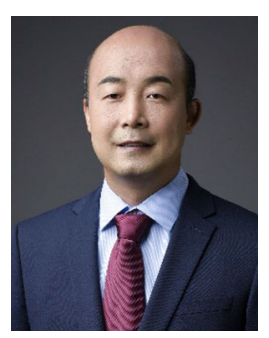

Wenjie ZHAO. He received his Ph.D. degree in materials science from Lanzhou Institute of Chemical Physics, Chinese Academy of Sciences, in 2010. Then, he joined the Key Laboratory of Marine Materials and Related Technologies

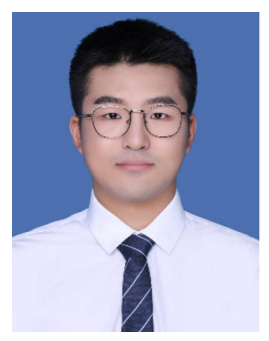

Wenchao ZHAO. He received his bachelor degree in materials science and engineering from Southwest Jiaotong University, Chengdu, China.

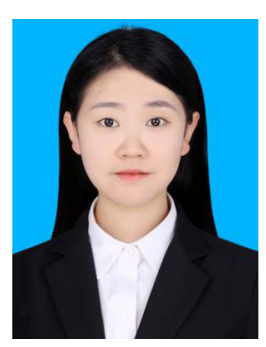

Xiaojing CI. She received her bachelor degree in material science and engineering in 2017 from Nanjing Technology University,

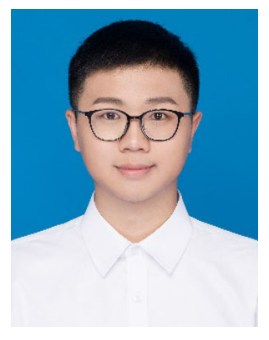

Wentao LI. He received his bachelor degree in materials engineering from Jiangxi University of Science
Nanchang, China. After then, he was a master student in the University of Chinese Academy of Sciences, Beijing, China. His research interests include tribology and corrosion of marine materials.

at Ningbo Institute of Materials Technology and Engineering, Chinese Academy of Sciences. His current position is a professor of the laboratory. His research areas cover the tribology of composite materials, 2D nanomaterials preparation, interfacial physical chemistry and protective coatings.

After then, he was a master student in the University of Chinese Academy of Sciences, Beijing, China. His research interests include tribology and corrosion of marine materials

Nanjing, China. After then, she was a master student in Shanghai University. Her research interests include 2D-materials and lubrication. and Technology in 2020. His research areas cover the tribology of polymer coating and modification of graphene. 